- Original Article-

\title{
Application of a wearable GPS unit for examining interindividual distances in a herd of Thoroughbred dams and their foals
}

\author{
Fumio SATO ${ }^{1,2 *}$, Tomoki TANABE ${ }^{3}$, Harutaka MURASE ${ }^{1}$, Masataka TOMINARI $^{1}$ and \\ Masahito KAWAI ${ }^{4}$ \\ ${ }^{1}$ Department of Equine Breeding Science, Hidaka Training and Research Center, Japan Racing Association, \\ Hokkaido 057-0171, Japan \\ ${ }^{2}$ United Graduate School of Veterinary Sciences, Gifu University, Gifu 501-1193, Japan \\ ${ }^{3}$ Graduate School of Environmental Science, Division of Biosphere Science, Hokkaido University, \\ Hokkaido 060-0810, Japan \\ ${ }^{4}$ Shizunai Livestock Farm, Field Science Center for Northern Biosphere, Hokkaido University, Hokkaido 056-0141, \\ Japan
}

Global positioning system (GPS) units are now lightweight and compact. They have proven useful for analyzing the behavioral characteristics of horses in pastures. Because the GPS records data in latitude and longitude, it may be feasible to calculate the distance between GPS units. The present study aimed to confirm the applicability of GPS units in behavioral studies on horses. For this, we analyzed the accuracy of the distances calculated from

J. Equine Sci.
Vol. 28, No. 1
pp. 13-17, 2017 GPS units using Hubeny's distance formula and of the monthly changes in interindividual distances obtained from GPS units worn by Thoroughbred dams and their foals in a pasture until weaning. The calculated inter-GPS distances were highly accurate. The regression line was linear, and the squared correlation coefficient $\left(r^{2}\right)$ was 0.9998. During the first month of age, the interindividual dam-dam and foal-foal distances were significantly greater than the dam-foal distance. During the second month of age, the dam-foal distance increased once and gradually decreased up to the fifth month of age. During the sixth month of age, the dam-foal distance was significantly greater than the foal-foal distance. The GPS distances calculated using Hubeny's distance formula were useful for analyzing changes in interindividual distances in a herd of Thoroughbred dams and their foals. Most likely, calculation of the distance between GPS units worn on equine head collars is likely to become a very useful tool as an objective index for quantifying equine behavioral observations.

Key words: dam, foal, GPS, interindividual distance, Thoroughbred

Examining locomotion and behavioral characteristics in a herd of Thoroughbred dams and their foals is crucial, as it provides data to facilitate the management of equine breeding in a pasture. Conventionally, such studies have

Received: September 20, 2016

Accepted: October 31, 2016

*Corresponding author. e-mail: Fumio_Sato@jra.go.jp

(C)2017 Japanese Society of Equine Science

This is an open-access article distributed under the terms of the Creative Commons Attribution Non-Commercial No Derivatives (by-nc-nd) License. (CC-BY-NC-ND 4.0: https://creativecommons.org/licenses/ by-nc-nd/4.0/) been conducted by visual observations of behavior [6, 10]. Recently, global positioning system (GPS) units have become sufficiently lightweight, thereby facilitating the measurement of movement and speed variables in horses not only during exercise training [7] but also in dams and foals in a pasture [5]. Using GPS units to analyze the amount of locomotion or the behavioral characteristics of horses in a pasture is more objective and simpler than visual observations of their behavior. An advantage of this approach is that it can be used regardless of weather conditions and the time of the day. Furthermore, based on GPS coordinate data on the latitude and longitude of the unit, it might be possible 
to measure the distance between two different GPS units [4]. This approach would also be applicable for measuring interindividual distances in a herd of horses in a pasture. However, few previous studies have sought to develop methods for measuring the distance between wearable GPS units worn on Thoroughbred horses in a pasture.

This study aimed to examine the accuracy of the distances measured by two different GPS units in a Thoroughbred horse's pasture. Furthermore, we used GPS units to measure the monthly changes in interindividual distances in a herd of Thoroughbred dams and their foals until weaning.

\section{Materials and Methods}

\section{GPS unit}

We used a commercially available GPS logger (Trip Recorder 747Pro, Transystem Inc., Hsinchu, Taiwan), which is compact ( $47 \mathrm{~W} \times 72 \mathrm{~L} \times 20 \mathrm{H} \mathrm{mm}$ ) and lightweight $(65 \mathrm{~g})$. It allowed at least $24 \mathrm{hr}$ of operation time and was suitable for placing on an equine head collar.

\section{Calculation of the distance between GPS units}

Distances between individual GPS units were calculated from the data on latitude and longitude in degrees that were acquired from each GPS unit. The calculations were based on Hubeny's distance formula, as described in a previous study [11]. The Excel (Microsoft Office Excel 2010, Japan Microsoft Inc., Tokyo, Japan) function shown below was used for the calculations.

\section{$\mathrm{D}=\operatorname{sqrt}\left((\mathrm{M} * \mathrm{dP})^{\wedge} 2+\left(\mathrm{N}^{*} \cos (\mathrm{P})^{*} \mathrm{dR}\right)^{\wedge} 2\right)$}

In this formula, $\mathrm{D}$ is the distance in meters $(\mathrm{m})$ between GPS units located at two points ( $\mathrm{X}$ and $\mathrm{Y}$ ), dP is the difference between the latitudes of the two points, $d R$ is the difference between the longitudes of the two points, $\mathrm{P}$ is the average latitude of the two points, $M$ is the radius of the curvature of the meridian, and $\mathrm{N}$ is the transverse radius of the curvature, as shown in the Excel functions below. As the data sets were projected onto the Bessel ellipsoid datum, we used the following ellipsoid parameters: 6,377,397 m for the major axis (a) and 6,356,079 $\mathrm{m}$ for the minor axis. The square of the first eccentricity $\left(\mathrm{e}^{2}\right)$ is 0.006674 , and the value of " $a *\left(1-\mathrm{e}^{2}\right)$ " for calculating the curvature of the meridian $(\mathrm{M})$ is $6,334,832$.

$$
\begin{aligned}
& \mathrm{d} P=((\text { latitude:X)-(latitude:Y) }) * \mathrm{PI}() / 180 \\
& \mathrm{dR}=((\text { longitude:X)-(longitude:Y) }) * \mathrm{PI}(\mathrm{)} / 180 \\
& P=((\text { latitude:X)+(latitude:Y }))^{*} \mathrm{PI}() /(180 * 2) \\
& \mathrm{M}=6,334,832 / \operatorname{sqrt}\left((1-0.006674 * \sin (\mathrm{P}) * \sin (\mathrm{P}))^{\wedge} 3\right) \\
& \mathrm{n}=6,377,397 / \operatorname{sqrt}(1-0.006674 * \sin (\mathrm{P}) * \sin (\mathrm{P}))
\end{aligned}
$$

\section{Evaluation of the accuracy of the between GPS distances}

To confirm the accuracy of the calculated distances, four
GPS units were placed at four different measured points $(0,20,50$, and $150 \mathrm{~m})$ in the pasture. The location data of each GPS unit were logged every $5 \mathrm{sec}$ from 12:00 pm to 7:00 am and loaded into a comma-separated value (CSV) files using GPS software (GPS Photo Tagger ver. 1.2.4, Transystem Inc.). The location data in the CSV files were then re-expressed as column data sets using Microsoft Excel software (Microsoft Office Excel 2010, Japan Microsoft Inc.). The distances between all combinations of the GPS units $(0,20,30,50,100,130$, and $150 \mathrm{~m})$ were calculated using Hubeny's distance formula, as described above.

\section{Horses}

The study subjects, a herd of Thoroughbreds comprising six dams and their foals (four colts and two fillies), were observed at a private breeding farm located in Hidaka $\left(42^{\circ} 15^{\prime} \mathrm{N}, 142^{\circ} 83^{\prime} \mathrm{E}\right)$, Hokkaido Prefecture, Japan. The ages of the dams varied from 7 to 21 years. At this farm, foals are normally born between March 9th and March 23rd. From April to October, the horses could graze every day as a herd on a rectangular field of $125 \times 175 \mathrm{~m}^{2}$ in size. The field was sown with grass conditioning mix together with Kentucky bluegrass (Poa pratensis) and white clover (Trifolium repens). From April to May, the herd grazed daily in the field from 6:00 am to 4:00 pm. From June to September, the herd grazed overnight in the field from 2:30 pm to 7:00 am. The foals were weaned simultaneously in October.

\section{GPS data collection and calculation of interindividual distances}

From the first to sixth months of foal age (from April to September), the GPS units, contained in a small Ziploc bag, were attached with a plastic tape to the ventral side of the head collars of all horses once a month (Fig. 1). These sessions were conducted for a period of $600 \mathrm{~min}$ from morning to evening during the first and second months of foal age and for a period of 1,000 min from the afternoon to the next morning during the third to sixth months of foal age. The latitude and longitude data from each GPS unit were logged every $5 \mathrm{sec}$ and loaded as Excel data. All data were exactly aligned with the correct time tag. Missing points were visually confirmed and corrected. Subsequently, the interindividual dam-foal distances and the nearest interindividual foal-foal and dam-dam distances were then calculated using Hubeny's distance formula, as described above.

\section{Statistical analyses}

Differences in mean values were assessed with multiple comparison procedures using commercially available statistical software (JMP 9, SAS Institute Inc., Cary, NC, U.S.A.). The average interindividual distances for all groups 
Table 1. Calculated distances between GPS units by Hubeny's distance formula

\begin{tabular}{lccccccc}
\hline \multicolumn{1}{c}{ Distance $(\mathrm{m})$} & 0 & 20 & 30 & 50 & 100 & 130 & 150 \\
\hline Average $(\mathrm{m}) \pm \mathrm{SD}$ & $2.8 \pm 1.1$ & $20.5 \pm 1.8$ & $30.4 \pm 1.7$ & $50.8 \pm 1.4$ & $99.8 \pm 1.3$ & $130.2 \pm 1.8$ & $150.5 \pm 1.2$ \\
Maximum $(\mathrm{m})$ & 6.5 & 26.1 & 34.7 & 55.5 & 103.2 & 134.0 & 154.5 \\
Minimum $(\mathrm{m})$ & 0.4 & 16.3 & 26.7 & 47.1 & 96.7 & 125.9 & 147.2 \\
\hline
\end{tabular}

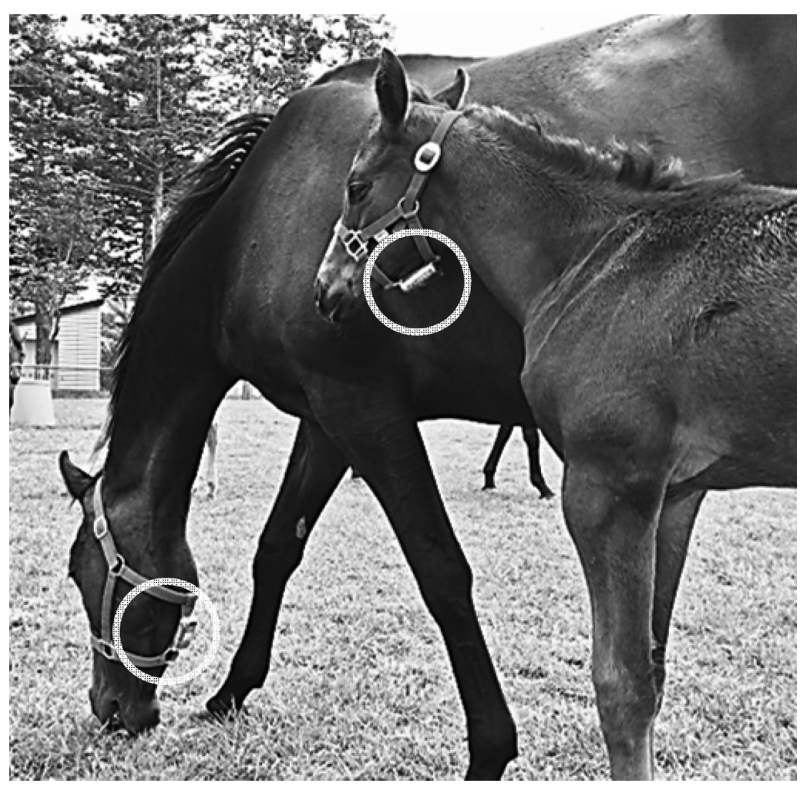

Fig. 1. Photograph of global positioning system (GPS) units on the ventral sides of the head collars (white circles) of a dam and a 2-month-old foal.

(dam-foal, foal-foal, and dam-dam) at the same sampling points (age in months) were analyzed using the Steel-Dwass method. The average interindividual distances for all months in each group were analyzed relative to a comparison value for the first month with the Steel method.

\section{Results}

\section{Evaluation of the accuracy of between-GPS distances}

Each point of GPS location data was logged every $5 \mathrm{sec}$ for $19 \mathrm{hr}$, resulting in a total of 13,680 observations. The mean, maximum, and minimum values of all combinations of distances $(0,20,30,50,100,130$, and $150 \mathrm{~m})$ between the four location points of GPS units, calculated by Hubeny's distance formula, are shown in Table 1. The regression line relating the true distance $(\mathrm{x})$ to the measured distance $(\mathrm{y})$ is given by $\mathrm{y}=0.9902 \mathrm{x}+1.3816$, and the squared correlation coefficient $\left(r^{2}\right)$ is 0.9998 .

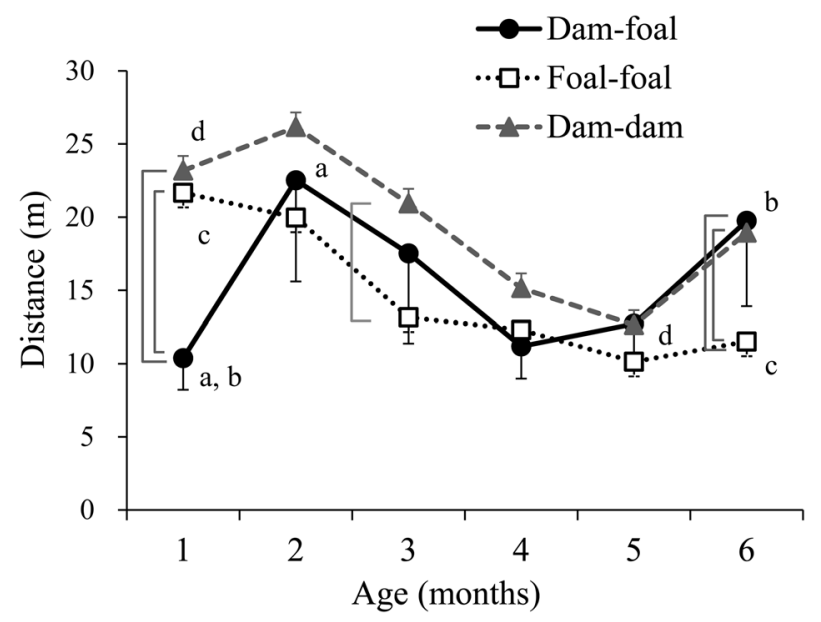

Fig. 2. Age-related changes in the interindividual dam-foal, dam-dam, and foal-foal distances obtained from GPS units. Mean distances \pm SD are plotted. Bars indicate significant differences between two groups at the same sampling point $(P<0.05)$. The same letters (a, b, c, and d) indicate significant differences from the first month of age $(P<0.05)$.

\section{Determination of interindividual dam-foal distances from GPS data}

Age-related changes in the interindividual dam-foal distances, as determined from GPS data, are shown in Fig. 2. In the first month of foal age, the mean value of the dam-foal distance was significantly lower than the mean foal-foal and dam-dam distances $(P<0.05)$. After the second month of foal age, the dam-foal distances were close to the dam-dam and foal-foal distances. The dam-foal, dam-dam, and foal-foal distances gradually decreased till the fifth month of foal age. In the third month of foal age, the foal-foal distances were significantly lower than the dam-dam distances $(P<0.05)$. Furthermore, in the sixth month of foal age, the foal-foal distances were lower than the dam-foal and dam-dam distances $(P<0.05)$.

\section{Discussion}

The size and weight of the GPS unit employed in this study were suitable for attaching the unit onto an equine head collar, and the battery operation time of the GPS unit 
was thought to be a sufficient for collecting the data from horses in this study. The GPS unit itself had no demerits, but the fully charging of the battery took about three hours, so it might be useful to prepare some spare GPS units if data needs to be collected on several consecutive days.

The nominal accuracy of the moving distance of the GPS unit used in the present study was less than $3.0 \mathrm{~m}$. The mean distances between GPS units, as calculated by Hubeny's distance formula, showed an error of less than 0.8 $\mathrm{m}$ for each estimated distance. The maximum and minimum values showed an error of less than $6.5 \mathrm{~m}$, almost twice that of the nominal accuracy value. Furthermore, the regression relationship between true and calculated values was linear, with a high correlation coefficient. These findings confirmed that the accuracy of the calculated between-GPS distances was very high.

In this study, we used the Bessel ellipsoid datum for calculating the between-GPS distances in Hubeny's distance formula. Recently, the new World Geodetic System WGS84 has been adopted as the reference system for GPS units. At the scale of a pasture, use of the Bessel ellipsoid datum parameters is not at all problematic for practical uses compared with use of the WGS84 parameters. If a researcher prefers to use the WGS84 parameters, the values to be applied would be as follows: $6,378,137 \mathrm{~m}$ for the major axis (a), 6,356,752 $\mathrm{m}$ for the minor axis, 0.006694 for the square of the first eccentricity $\left(\mathrm{e}^{2}\right)$, and $6,335,439$ for the value of " $\mathrm{a} *\left(1-\mathrm{e}^{2}\right)$ " for calculating the curvature of the meridian $(\mathrm{M})$.

Because investigations on the interindividual distances of horses in a pasture were previously been conducted using periodic visual observations based on body lengths $[1,3$, $6,8]$, it was not possible to calculate exact interindividual distances or to observe behaviors continuously throughout the day. Kusunose et al., reported that the change in interindividual distance between a dam and her foal increased till 9 weeks after birth, was relatively constant from 9 to 22 weeks, and then increased again [6]. Another study reported that suckling frequency rapidly declined in the second month and continued decreasing until the 10th month [3]. In the present study, it was possible to calculate the interindividual dam-foal, dam-dam, and foal-foal distances during almost all periods in the pasture using GPS units and to analyze the changes in interindividual distances with age. We found that dam-foal distances were very small till the first month of age, whereas the dam-dam and foal-foal distances were significantly longer. Because foals spend most of their time with their mother in the first weeks of life, the above suggests that the mares were spread apart in the pasture [8]. At the second month of age, the dam-foal distance increased once, and there were no significant differences between the dam-dam and foal-foal distances. The dam-foal distance then began to decrease gradually till the fifth month of foal age. Play between a mare and her foal decreases as the foal spends an increasing amount of time with its peers [8]. A rapid increase in time spent grazing by a foal occurs after 4 months of age [9]. The dam-foal distance till the fifth month of age might to be close to the dam-dam distance, which were proportional to the size of the herd. Just before weaning at 6 months of age, the dam-foal distance significantly increased compared with the foal-foal distance. Contact between foals appeared to increase. Although the changes in interindividual distances analyzed by Hubeny's distance formula using GPS data supported the previous research data obtained through behavioral observations, it is likely possible to calculate exact interindividual distances throughout the day.

In recent years, the use of a gravitational force data logger has also been reported in research on equine standing and lying behaviors [2]. Use of this device in combination with a GPS unit would enable more detailed behavioral analyses of horses in pasture. Behavioral studies on horses are a very crucial component of equine research for feeding and breeding management. Calculating the distance between GPS units worn on equine head collars is likely to become a very useful tool for obtaining objective values in equine behavioral observations. We hope that the further studies are carried out using this GPS method under various pasture conditions and under various management conditions.

\section{Acknowledgments}

We are grateful to the farm in Urakawa town for their cooperation in this study. The authors have no conflicts of interest.

\section{References}

1. Cameron, E.Z., Linklater, W.L., Stafford, K.J., and Minot, E.O. 2003. Social grouping and maternal behavior in feral horses (Equus caballus): the influence of males on maternal protectiveness. Behav. Ecol. Sociobiol. 53: 92-101.

2. DuBois, C., Zakrajsek, E., Haley, D.B., and Merkies, K. 2015. Validation of triaxial accelerometers to measure the lying behaviour of adult domestic horses. Animal 9: 110-114. [Medline] [CrossRef]

3. Heitor, F., and Vicente, L. 2008. Maternal care and foal social relationships in a herd of Sorraia horses: influence of maternal rank and experience. Appl. Anim. Behav. Sci. 113: 189-205. [CrossRef]

4. Jennings, D., Cormack, S., Coutts, A.J., Boyd, L.J., and Aughey, R.J. 2010. Variability of GPS units for measuring distance in team sport movements. Int. J. Sports Physiol. Perform. 5: 565-569. [Medline] [CrossRef]

5. Kurvers, C.M., van Weeren, P.R., Rogers, C.W., and van 
Dierendonck, M.C. 2006. Quantification of spontaneous locomotion activity in foals kept in pastures under various management conditions. Am. J. Vet. Res. 67: 1212-1217. [Medline] [CrossRef]

6. Kusunose, R., and Sawazaki, H. 1984. Individual differences in the behavior of Thoroughbred dam and their foal. Jpn. J. Zootech. Sci. 55: 272-278.

7. Kusunose, R., and Takahashi, T. 2002. Reliability of EquiPILOT $^{\circledR}$ for measuring aerobic fitness in racehorses. J. Equine Sci. 13: 117-121. [CrossRef]

8. McGreevy, P. 2012. Equine behavior. pp. 227-231. In: Play of Body Care (Chapter 10), 2nd ed. (Edwards, R. ed.),
Elsevier Saunders, Amsterdam.

9. McGreevy, P. 2012. Equine behavior. pp. 187-189. In: The Transition from Milk to Solids of Ingestive Behavior (Chapter 8), 2nd ed. (Edwards, R. ed.), Elsevier Saunders, Amsterdam.

10. Shingu, Y., Kawai, M., Inaba, H., Kondo, S., Hata, H., and Okubo, M. 2000. Voluntary intake and behavior of Hokkaido native horses and light half-bred horses in woodland pasture. J. Equine Sci. 11: 69-73. [CrossRef]

11. Tsuboi, T., and Oguri, K. 2013. Advanced ITS application for natural disaster protection. Int. J. Com. Net. Tech. 3: $159-170$. 